\title{
Acoustic evaluation of wood quality with a non-destructive method in standing trees: a first survey in Italy
}

\author{
Andrea R Proto ${ }^{(1)}$, \\ Giorgio Macrì ${ }^{(1)}$, \\ Vincenzo Bernardini ${ }^{(2)}$, \\ Diego Russo ${ }^{(1)}$, \\ Giuseppe Zimbalatti ${ }^{(1)}$
}

\begin{abstract}
Research and development efforts are currently underway worldwide to examine the potential use of a wide range of non-destructive technologies (NDT) for evaluating wood and wood-based materials, from the assessment of standing trees to in-place structures. For this purpose, acoustic velocity by the Fakopp time of flight (TOF) tool was used to estimate the influence of four thinning treatments performed in Southern Italy. The objective of the study was to determine if the effects of silvicultural practices on wood quality can be identified using acoustic measurement to assess the MOEd of standing trees with non-destructive method in Calabrian pine (Pinus nigra Arnold subsp. calabrica). Four hundred and fifty standing trees from four sites were nondestructively tested using a time-of-flight acoustic wave technique. The thinning trials were conducted on 60-year-old plantations of Calabrian pine in four plots under different treatments: Control $(T)$, light thinning $(A)$, intermediate thinning (B) and heavy thinning (C). Statistical analysis demonstrated significant stress wave time differences between the stands with moderate thinning (A and B) and those with heavy thinning (C). The results showed that tree diameter has significant influence on acoustic wave measurements and a valid relationship exists between diameter at breast height and tree velocity. The results of these studies proved that the stress wave technique can be successfully applied on standing trees.
\end{abstract}

\section{Keywords: Modulus of Elasticity, Wood Density, Thinning, Calabrian Pine}

\section{Introduction}

Assessing the wood quality of individual trees and overall forest stands has become an important procedure in forest operations, as forestry and wood processing industries are under increasing economic pressure to maximize extracted value (Wang et al. 2007a). For this reason, the estimation of timber species, quantity, and quality is critical for quantifying the productive value of a forest (Marziliano et al. 2012, Proto et al. 2014). The worldwide shift in the wood supply from old-growth for ests resources to intensively managed plantations increases the need of evaluating tree quality prior to harvest (Wang $\&$ Ross 2008).

Significant efforts have been made to de-

velop robust, non-destructive technologies (NDT) capable of predicting the intrinsic wood properties of individual living trees and assessing wood quality by stand and forest. In addition, non-destructive technologies including (mini) rhizotrons and ground-penetrating radar have been recently proposed to assess plant rooting distribution and growth (Sanesi et al. 2013, Marziliano et al. 2015). The use of such technologies not only leads to greater profitability for the forest industry, but can also help foresters to make economic and environmental management decisions for treatment of individual trees and forest stands, improve thinning and harvesting operations, and efficiently allocate timber resources for optimal utilization (Wang et $\square$ (1) Department of Agriculture, Mediterranean University of Reggio Calabria, Feo di Vito 89122, Reggio Calabria (Italy); (2) Italian Council for Agricultural Research and Economics Mediterranean Forestry Research Unit (CREA - SAM) - C.da Li Rocchi, Vermicelli, 87036 Rende, CS (Italy)

@ Andrea R Proto (andrea.proto@unirc.it)

Received: Mar 23, 2016 - Accepted: Apr 18, 2017

Citation: Proto AR, Macrì G, Bernardini V, Russo D, Zimbalatti G (2017). Acoustic evaluation of wood quality with a non-destructive method in standing trees: a first survey in Italy. iForest 10: 700-706. - doi: 10.3832/ifor2065-010 [online 2017-07-17]

Communicated by: Giacomo Goli al. 2007a, Proto et al. 2014). Acoustic technologies have become well established as material evaluation tools, and their use has become widely accepted for quality control by the wood industry (Wang et al. 2007b). With the development of portable and simple-to-use, time-of-flight and resonancebased tools, the use of acoustics in the forestry sector has increased, particularly in countries such as New Zealand (Walker \& Nakada 1999, Tseheye et al. 2000, Chauhan \& Walker 2006), Australia, USA (Wang et al. 2001, 2004), Hungary (Brashaw et al. 2009, Divos 2010) and the United Kingdom (Searles \& Moore 2009). In Japan, Nakamura (1996) used ultrasonically-induced waves to assess larch trees and observed significant differences in acoustic velocities and modulus of elasticity (MOE) for trees in forest stands at different locations and with different density. The non-destructive technologies, equipment, and evaluation procedures arising from those efforts are now widespread, and their use is becoming more and more common also for European forest industries. This paper reports a case study using these tools in managed conifer forests in Italy.

The objective of the study was to determine if the effects of silvicultural practices on wood quality can be identified using acoustic measurement to assess the MOEd (dynamic modulus of elasticity) of standing trees with non-destructive method in Calabrian pine (Pinus nigra Arnold subsp. Cal- 
abrica) plantations. In Calabria, where the tests were conducted, forest cover is $40.6 \%$ compared to the national average of $34.7 \%$. Each year, the average increase in wood volume in this region (equal to $6-8 \mathrm{~m}^{3} \mathrm{ha}^{-1}$ ) exceeds and sometimes doubles the estimated increase in other forests in and around southern Italy (Zimbalatti \& Proto 2009, Proto \& Zimbalatti 2016). A secondary aim was to determine if the effects of silvicultural practices on wood quality can be identified using this technique.

\section{Materials and methods}

\section{The time-of-flight method}

The system used for measuring acoustic velocity in trees involves inserting two sensor probes (a transmit probe and a receiver probe) into the sapwood for few centimetres in a vertical plane, according to the manufacturer's instructions, and introducing acoustic energy into the tree through a hammer impact. Wave propagation velocity in the tree is determined by measuring the time-of-flight of a single pulse wave. Time-of-flight (TOF) essentially measures the time for the stress wave to travel from the transmit probe to the receiver probe. Piezoelectric sensors inside the two probes are used to sense the wave passing.

The acoustic velocity is then calculated from the distance between the two sensor probes and the TOF data using the following equation (eqn. 1):

$$
C T=\frac{S}{\Delta T}
$$

where $C T$ is the acoustic velocity $\left(\mathrm{m} \mathrm{s}^{-1}\right), S$ is distance between the two probes (sensors) ( $\mathrm{m})$, and $\Delta T$ is the time-of-flight (s).

The FAKOPP TreeSonic ${ }^{T M}$ (Fakopp Enterprise, Agfalva, Hungary) is an acoustic tool specifically designed to study standing trees (Booker \& Ridoutt 1997, Lindstrom et al. 2002, Huang 2005, Chauhan \& Walker 2006, Brashaw et al. 2009, Divos 2010, Wang 2011, 2013). The tool is comprised of a hand-held hammer and two probes, a transmitting accelerometer, and a receiving accelerometer. The vibration transducers (patented by the Weyerhaeuser Company) are equipped with a sliding hammer, resulting in quick operation (Huang \& Lambeth 2006). To measure the acoustic velocity wave, the start and stop sensors are driven through the bark at a $45^{\circ}$ angle into the wood of the standing tree. Unlike other similar tools (Hitman Resonance Tool, IML Impulse Hammer and Microsecond FAKOPP) which are specifically modelled for radial measurement, the FAKOPP TreeSonic ${ }^{T M}$ was developed to operate in the longitudinal direction along the stem (Fig. 1). During field acoustic measurements, the probes are aligned within a vertical plane on the same face.

For this study, a 1.00-meter testing span was roughly centered at breast height. The lower probe was placed about $40-60 \mathrm{~cm}$ above the ground. In conjunction with the acoustic measurement, the diameter at breast height of each tree was measured according to the common practice in forestry measurement (Proto \& Zimbalatti 2016). Four readings in the same position were recorded for each tree. Stress wave times were then converted to mean acoustic velocity for each tree.

\section{The modulus of elasticity equation}

The next step was to calculate the modulus of elasticity, which is the most important parameter in assessing wood quality. The dynamic modulus of elasticity (MOEd Urhan et al. 2014) can be estimated from

Fig. 1 - Schematic representation of the acoustic wave system used for field-testing of standing trees.

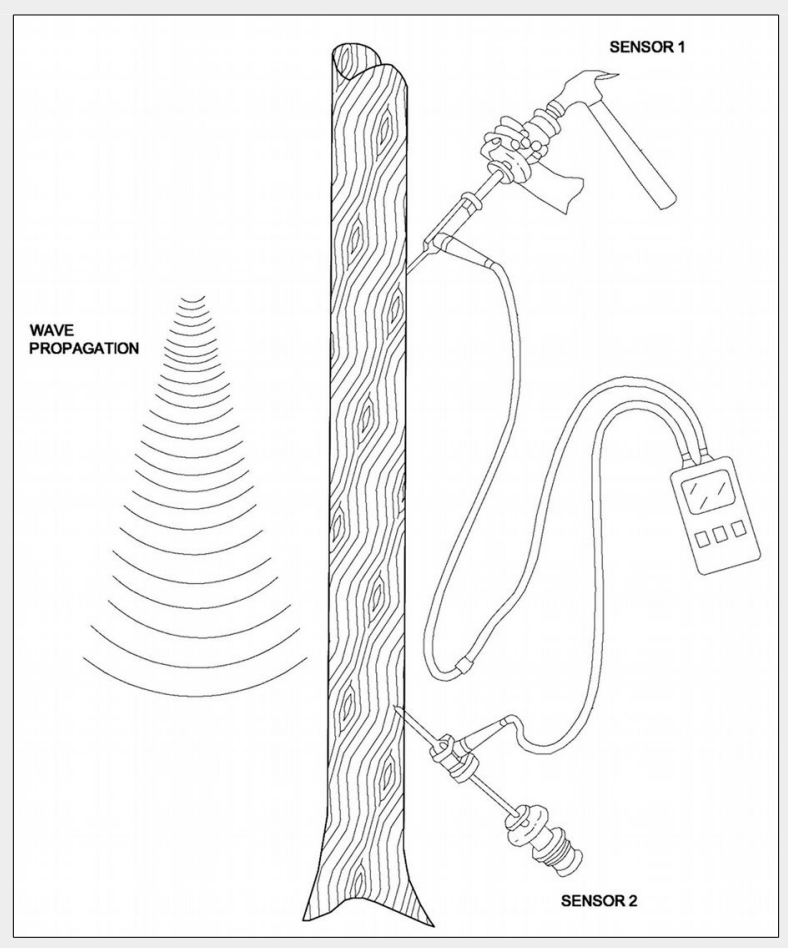

the velocity of acoustic waves (acoustic velocity, $(T)$ passing through the wood, according to the following formula (eqn. 2):

$$
M O E d=W D \cdot A V^{2}
$$

where WD is the wood density, expressed in $\mathrm{kg} \mathrm{m}^{-3}$, and $A V$ is the velocity in $\mathrm{km} \mathrm{s}^{-1}$ (Pellerin \& Ross 2002, Chauhan et al. 2005, Lasserre et al. 2007). Wood density was determined by volumetric methods, which required measuring the volume and mass of dry wood in the laboratory. The density was computed starting from basic density measured on a small wood core (roughly 10 $\times 10 \mathrm{~mm}$, after removing the bark) taken from the same section of the stem where the NDT measurement was carried out. To compute the basic density, the oven-dry mass $(\mathrm{MCO} \%)$ was divided by its green volume, and measured based on the Archimedes' law using a beaker with distilled water placed on a lab electronic balance (0.001 $\mathrm{g}$ of resolution) set to zero; a mechanical arm connected to the needle able to correctly immerse the wood specimen in the water, the top of the wood being just below the meniscus, thus avoiding a significant immersion of the needle. A small specimen from the core was devoted to get the moisture content of the wood via gravimetric test (UNI-ISO-3130 1985). Although the specimens were green, they had been stored in distilled water for 48 hours in order to saturate the wood. From basic density raw data, by taking into account the shrinkage percentage (Sh\% = $100 \cdot$ [decrease in size/ original size], applying a shrinkage rate of 0.14 and $0.25 \%$ for every \% of $\mathrm{mc}$, respectively for radial and tangential directions - Sell \& Kropf 1990) from fibre saturation point down to $12 \%$ $\mathrm{MC}$, the normal density $\left(\mathrm{kg} \mathrm{m}^{-3} 12 \%\right)$ was computed. The original velocity recorded on green timber was considered, as it was not corrected according to the moisture content, following the manufacturer's specification.

\section{Study sites and tree samples}

Four research plots were selected in 60year-old Calabrian pine plantations located at Varco San Mauro in the municipality of Rose (Cosenza Tyrrhenian Presila). The four plots were previously subjected to different thinning treatments (Fig. 2): control ( $\mathrm{T}$ - no thinning, approx. 1300 trees ha-1); light thinning $\left(A-800\right.$ trees ha $\left.{ }^{-1}\right)$; intermediate thinning ( $B-600$ trees $\left.h^{-1}\right)$; and heavy thinning $\left(C-400\right.$ trees ha $\left.{ }^{-1}\right)$. Thinning treatments have been carried out at intervals of 8-10 years each other. Plots $A$, $B$, and $C$ were subsequently targeted for final harvest and regeneration. The historical information and the stand structural characteristics of the plots are reported in Tab. 1.

Field tree measurements and acoustic wave tests were conducted from October 2014 to February 2015. A total of 450 trees were tested and tagged with a unique 
Fig. 2 - The four treatments in the study area.
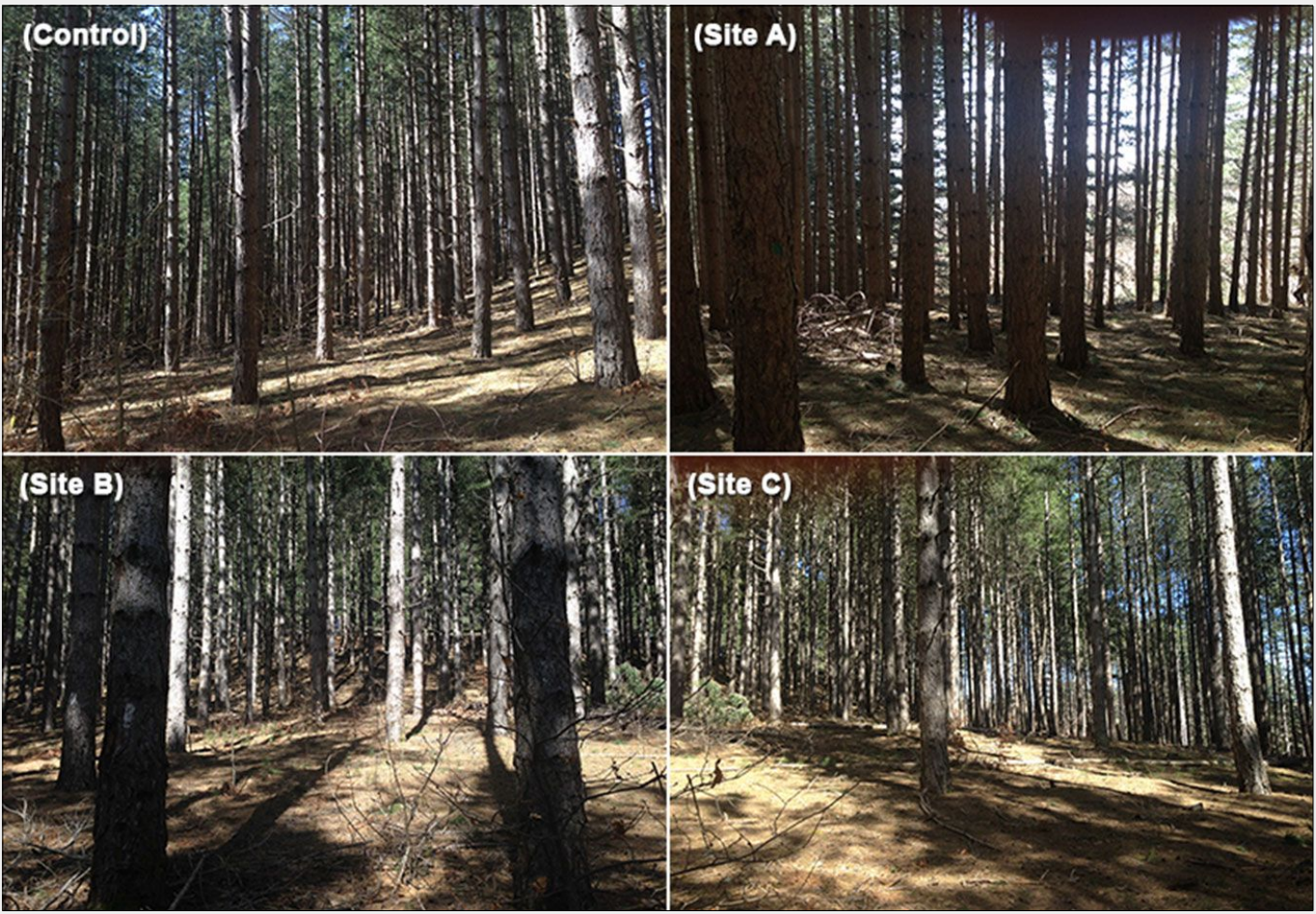

(Site C)
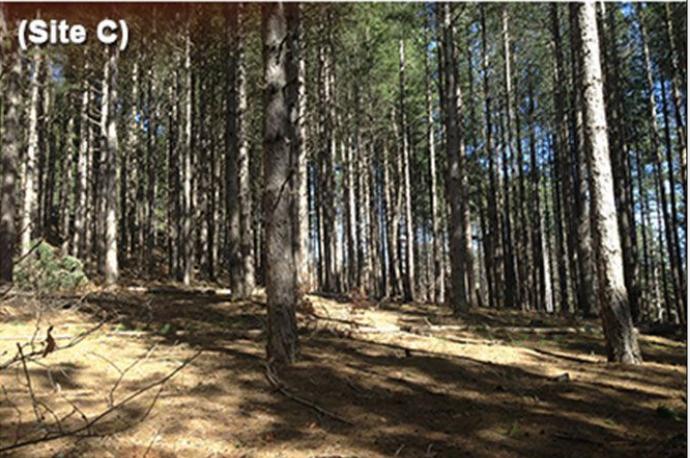

number. The sampled trees were stratified in four classes based on diameter at breast height (DBH): 30, 35, 40 and $45 \mathrm{~cm}$. Such classes were chosen as considered representative of the typical size for commercial trees.

\section{Statistical analysis}

Analysis of tree stress wave time and tree diameter at breast height was performed at both individual tree and site level. The tree diameter at breast height $(\mathrm{DBH}, \mathrm{cm})$ and tree density ( $d$, number of trees ha ${ }^{-1}$, varying across treatments) were selected as independent variables (two groups in mixed model), while MOEd (calculated from eqn. 2) was the dependent variable of the regression analysis (eqn. 3):

$$
\text { MOEd }=f(D B H, d)
$$

Analysis of variance (ANOVA) was conducted to test for differences in MOEd between DBH classes and thinning regimes. The post-hoc Tukey's test ( $\alpha=0.05)$ was applied to detect significant differences among group means.

The software packages SPSS ${ }^{\oplus}$ ver. 20.0 (IBM, Armonk, NY, USA) and MS Excel ${ }^{\circledR}$ 2012 (Microsoft, Redmond, WA, USA) were used for the analysis.

\section{Results}

The wood density computed from basic density measured on the collected specimens is reported in Tab. 2.

Mean Fakopp velocity did not significantly differ among treatments $\mathrm{T}, \mathrm{A}$ and $\mathrm{B}$ $(4.36 \pm 0.56$ SD, $4.57 \pm 0.29$ and $4.46 \pm 0.31$ $\mathrm{km} \mathrm{s}^{-1}$, respectively), whereas it was significantly lower in treatment C $(3.98 \pm 0.52 \mathrm{~km}$
Tab. 1 - Main characteristics of the plots selected for non-destructive evaluation of wood quality in Calabrian pine plantations. Thinnings were carried out in 1987, 1995 and 2005. (T): control; (A): light thinning; (B): intermediate thinning; (C): heavy thinning; (Hg): height $(\mathrm{m})$; $(\mathrm{DBH})$ : diameter at breast height $(\mathrm{cm})$; $(\mathrm{hg} / \mathrm{dbh})$ : slenderness coefficient or ratio; $(\mathrm{G})$ : basal area; $(\mathrm{V})$ : standing volume.

\begin{tabular}{|c|c|c|c|c|c|c|c|}
\hline Year & Plot & $\begin{array}{l}\text { Density } \\
\left(\mathrm{n} \mathrm{ha}^{-1}\right)\end{array}$ & $\begin{array}{l}\text { DBH } \\
(\mathbf{c m})\end{array}$ & $\begin{array}{l}\mathrm{hg} \\
(\mathrm{m})\end{array}$ & hg/DBH & $\begin{array}{c}G \\
\left(m^{2} h a^{-1}\right)\end{array}$ & $\begin{array}{c}V \\
\left(m^{3} h a^{-1}\right)\end{array}$ \\
\hline \multirow[t]{4}{*}{1987} & $T$ & 1651 & 22.0 & 14.45 & 66 & 62.71 & 477.84 \\
\hline & A & 1769 & 21.2 & 15.50 & 73 & 62.72 & 476.05 \\
\hline & B & 1699 & 22.1 & 15.07 & 68 & 65.42 & 497.85 \\
\hline & C & 1757 & 21.5 & 14.98 & 70 & 63.62 & 482.86 \\
\hline \multirow[t]{4}{*}{1995} & $\mathrm{~T}$ & 1460 & 25.4 & 18.12 & 70 & 74.26 & 674.98 \\
\hline & A & 1339 & 26.0 & 19.87 & 76 & 71.12 & 648.35 \\
\hline & B & 1176 & 27.4 & 19.35 & 71 & 69.39 & 636.48 \\
\hline & C & 1103 & 27.6 & 19.63 & 71 & 66.07 & 606.58 \\
\hline \multirow[t]{4}{*}{2005} & $\mathrm{~T}$ & 1460 & 27.5 & 22.25 & 81 & 86.87 & 796.39 \\
\hline & A & 1001 & 30.5 & 22.70 & 74 & 73.14 & 677.62 \\
\hline & B & 827 & 32.0 & 22.97 & 72 & 66.62 & 619.79 \\
\hline & C & 664 & 32.9 & 23.04 & 70 & 56.54 & 527.26 \\
\hline \multirow[t]{4}{*}{2015} & $\mathrm{~T}$ & 1315 & 30.9 & 27.79 & 90 & 97.55 & 905.84 \\
\hline & A & 803 & 34.2 & 28.13 & 82 & 72.58 & 670.30 \\
\hline & B & 605 & 36.6 & 27.89 & 76 & 60.61 & 569.94 \\
\hline & C & 407 & 38.1 & 28.37 & 74 & 47.36 & 458.21 \\
\hline
\end{tabular}

Tab. 2 - Wood density $\left(M_{12 \%}\right)$ computed from basic density of sample wood cores measured in the four study plots. $(T)$ : control; (A): light thinning; (B): intermediate thinning; (C): heavy thinning; (STD): standard deviation; (CoV): coefficient of variation.

\begin{tabular}{llcccc}
\hline Parameter & Statistic & T & A & B & C \\
\hline Stem density $\left(\mathrm{n} \mathrm{ha}^{-1}\right)$ & & 1315 & 803 & 605 & 407 \\
Specimens per area $(\mathrm{n})$ & & 118 & 115 & 111 & 106 \\
Tree wood density & Average $\left(\mathrm{kg} \mathrm{m}^{-3}\right)$ & 603 & 587 & 580 & 563 \\
$\left(\mathrm{MC}_{12 \%}\right)$ & STD $\left(\mathrm{kg} \mathrm{m}^{-3}\right)$ & 39.7 & 33.7 & 37.5 & 40.4 \\
& CoV $(\%)$ & 6.58 & 5.74 & 6.47 & 7.18 \\
& $5^{\text {th }}$ perc. $\left(\mathrm{kg} \mathrm{m}^{-3}\right)$ & 542 & 527 & 519 & 491 \\
& 95 $^{\text {th }}$ perc. $\left(\mathrm{kg} \mathrm{m}^{-3}\right)$ & 664 & 634 & 635 & 617 \\
\hline
\end{tabular}




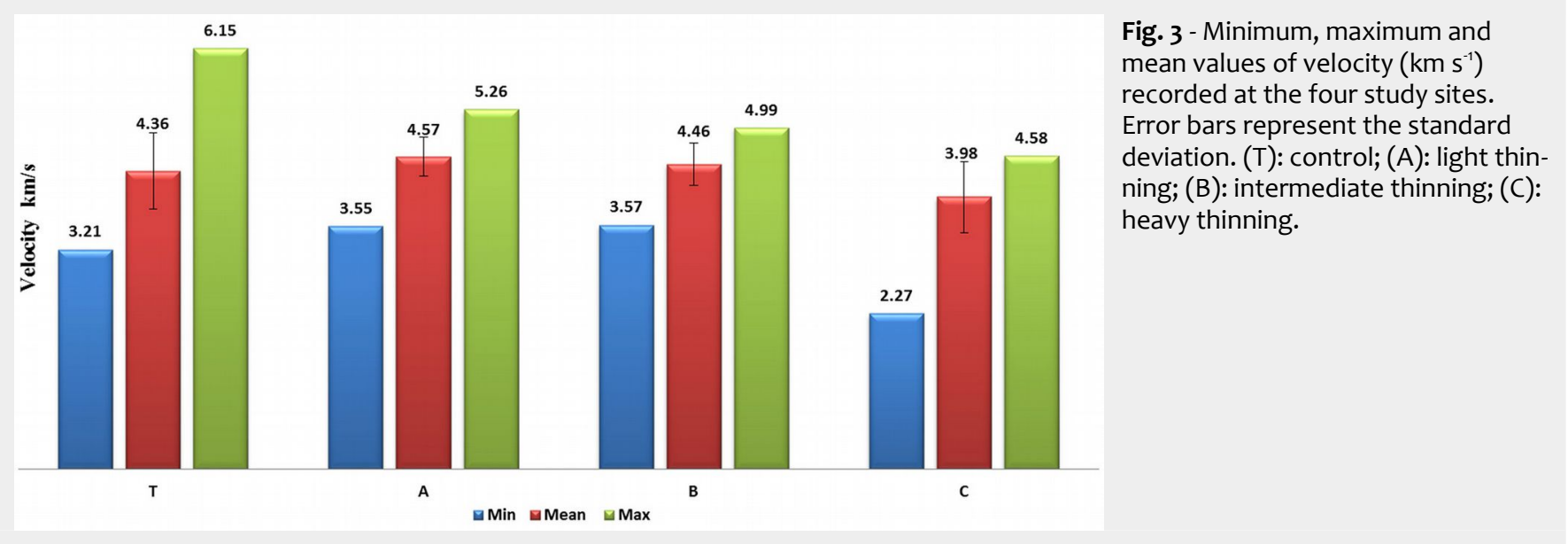

Tab. 3 - Data registered at the four study plots. (T): control; (A): light thinning; (B): intermediate thinning; (C): heavy thinning.

\begin{tabular}{|c|c|c|c|c|c|c|c|c|c|c|c|c|}
\hline \multirow{2}{*}{ Plot } & \multicolumn{4}{|c|}{ Stress wave time $(\mu \mathrm{s})$} & \multicolumn{4}{|c|}{ Fakopp Velocity $\left(\mathrm{km} \mathrm{s}^{-1}\right)$} & \multicolumn{4}{|c|}{ MOEd $(\mathrm{MPa})$} \\
\hline & Min & Mean & Max & St.Dev. & Min & Mean & Max & St.Dev. & Min & Mean & Max & St.Dev. \\
\hline$T$ & 162.4 & 233.5 & 303.8 & 31.8 & 3.21 & 4.36 & 6.15 & 0.56 & 5611.4 & 9982.98 & 19624.6 & 2580.0 \\
\hline A & 190.1 & 219.3 & 281.4 & 15.3 & 3.55 & 4.57 & 5.26 & 0.29 & 6537.0 & 10901.48 & 14328.1 & 1401.6 \\
\hline B & 200.0 & 225.3 & 279.4 & 16.8 & 3.57 & 4.46 & 4.99 & 0.31 & 6631.2 & 10352.71 & 12931.7 & 1454.6 \\
\hline C & 218.1 & 256.6 & 439.8 & 45.6 & 2.27 & 3.98 & 4.58 & 0.52 & 2677.3 & 8364.57 & 10885.3 & 1989.1 \\
\hline
\end{tabular}

$\mathrm{S}^{-1}$ - Fig. 3, Tab. S1 in Supplementary material). The average stress wave time of trees for plot A (light thinning) was about 5\% higher than for the control $(T)$; in plot $C$ (heavy thinning), the value was lower by about $9 \%$ (Tab. 3 ).

MOEd ranged from 6,537 to $14,328 \mathrm{MPa}$ (mean $=10,901 \mathrm{MPa}$ ) in plot $\mathrm{A}$, while in plot $B$ it varied from 6,631 to $12,931 \mathrm{MPa}$, with a mean of 10,352 MPa (Tab. 3). Statistical analysis revealed significant differences in MOEd between the stands with moderate thinning ( $A$ and $B$ ) and those with heavy thinning ( $C$ - Tab. S1 in Supplementary material). Moreover, the MOEd values estimated for treatment $C$ were lower than those for the control plot (Tab. 3).

Among the different diameter classes, the average MOEd of standing trees was the highest values of MOEd were registered for classes 30 and $35 \mathrm{~cm}$ (Fig. 4), though the differences were not statistically significant $(p>0.05)$. This suggests that the thinning treatment affects the wood quality of standing trees. Indeed, it is expected that, for trees of the same age, larger trees with higher growth rate generally produce wood of lower density and stiffness (Zhang 1995, Koubaa et al. 2000). Our results confirmed that light and moderate thinning produced significant benefits in terms of wood quality. The reduced stand density of plot $C$ promoted a faster radial growth, which led to a lower wood density of the mature trees.

The analysis of variance confirmed that significantly influenced by $\mathrm{DBH}$ and thinning regimes (Tab. 4). The results of the Tukey's test confirmed the existence of significant differences $(\mathrm{p}<0.05)$ in MOEd values among treatments (Tab. S1 in Supplementary material).

The results of the regression analysis carried out are reported in Tab. 5. Both parameters may be considered as fairly good predictors of MOEd, as they account for a significant portion of the total variance $\left(R^{2}=\right.$ 0.34). The regression model obtained was as follows (eqn. 4):

$$
\begin{aligned}
\text { MOEd } & =12556.68-52.852 \mathrm{DBH} \\
& -551.522 d
\end{aligned}
$$

where $D B H$ is the diameter at breast height $(\mathrm{cm})$, and $d$ is the stand density $\left(n \mathrm{na}^{-1}\right)$.

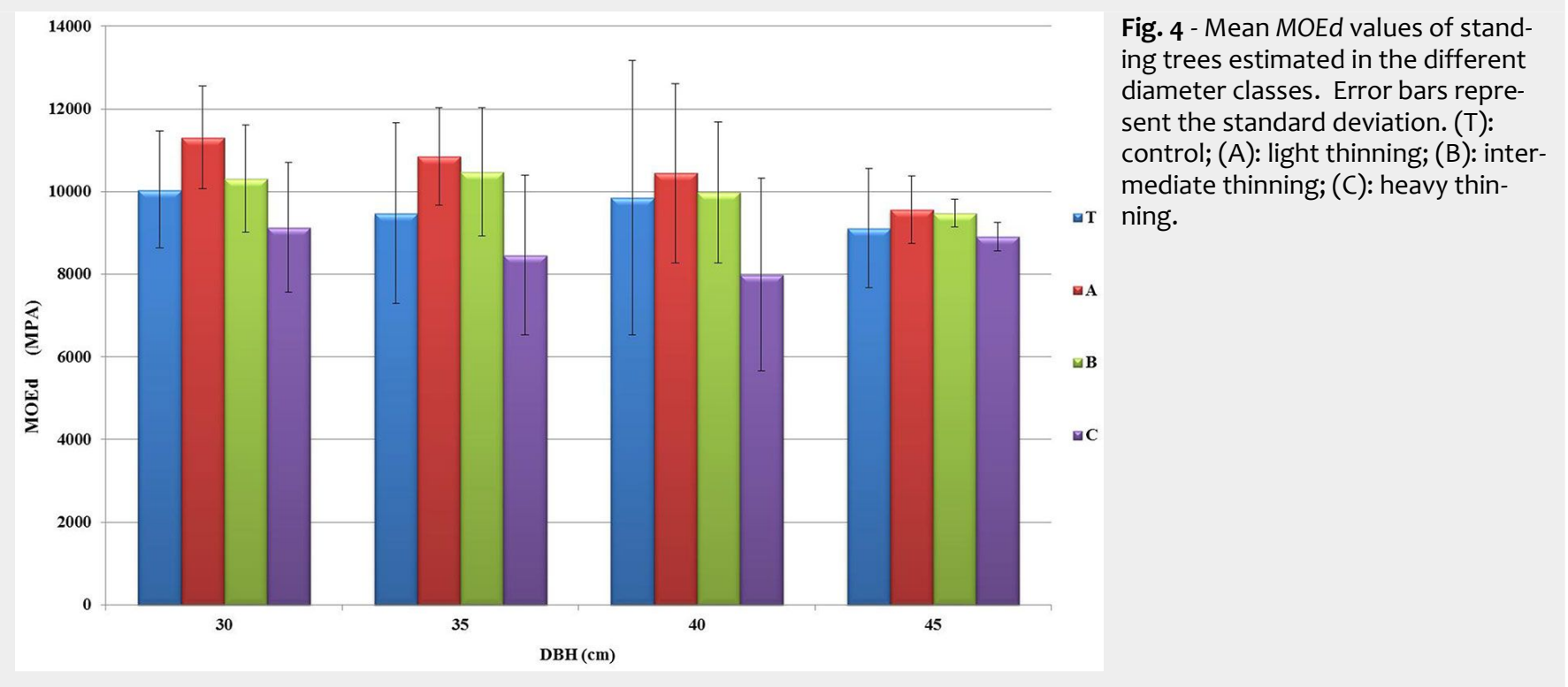


Tab. 4 - Results of the analysis of variance on MOEd values using tree DBH and treatment (stand density) as factors.

\begin{tabular}{llcrccc}
\hline Factor & Model & Sum of Squares & df & Mean Square & F & Prob \\
\hline Treatment & Between Groups & 153555296.89 & 3 & 51185098.965 & 15.460 & 0.000 \\
(tree & Within Groups & 635655126.90 & 192 & 3310703.786 & - & - \\
density) & Total & 789210423.79 & 195 & - & - & - \\
DBH & Between Groups & 282716298.739 & 35 & 8077608.535 & 2.552 & 0.000 \\
& Within Groups & 506494125.058 & 160 & 3165588.282 & - & - \\
& Total & 789210423.797 & 195 & - & - & - \\
\hline
\end{tabular}

Tab. 5 - Results of the regression analysis using $\mathrm{DBH}$ and treatment as predictors of MOEd.

\begin{tabular}{lrrcrrr}
\hline \multirow{2}{*}{ Variable } & \multicolumn{2}{c}{$\begin{array}{c}\text { Unstandardized } \\
\text { coefficients }\end{array}$} & $\begin{array}{c}\text { Standardized } \\
\text { coefficient }\end{array}$ & \multirow{2}{*}{$\boldsymbol{t}$} & Prob & \multirow{2}{*}{$\mathbf{R}^{2}$} \\
\cline { 2 - 5 } & \multicolumn{1}{c}{ B } & St.dev. & $\boldsymbol{\beta}$ & & & \\
\hline Constant & 12556.680 & 658.414 & - & 17.071 & 0.000 & 0.34 \\
DBH & -52.852 & 18.151 & -1.990 & -2.192 & 0.004 & \\
Treatment & -551.522 & 120.731 & -0.312 & -4.568 & 0.000 & \\
\hline
\end{tabular}

\section{Discussion}

This study demonstrates that the effect of silvicultural practices on wood properties can be successfully identified based on stress wave MOEd. Indeed, thinning caused a significant variation in terms of MOEd among DBH tree classes (Fig. 4). Similarly, Todaro \& Macchioni (2011) registered a significant variation of wood properties caused by thinnings in a Douglas-fir stand in Southern Italy. These results confirms that the reduction of stand density by thinning may cause a faster radial growth of the remnant trees, which involves a reduction of wood quality in terms of wood density and stiffness.

Acoustic waves based techniques aimed to assess the intrinsic wood properties of standing trees have been applied in many studies worldwide (Nanami et al. 1992, Wang 1999, Ikeda \& Kino 2000, Ikeda \& Arima 2000, Huang 2000, Wang et al. 2001, Lindstrom et al. 2002). Wang (2012) found that a range of wood and fibre properties can be predicted through a simple acoustic measurement of standing trees. Moreover, many studies reported that, for softwood trees of the same age, stress wave velocity is higher for trees with slower growth rates and narrower rings. The species tested included Sitka spruce (Picea sitchensis), western hemlock (Tsuga heterophylla), jack pine (Pinus banksiana), ponderosa pine (Pinus ponderosa), and radiata pine (Pinus radiata - Wang et al. 2003).

In this study, the repeated intensive thinnings in the plot $\mathrm{C}$ have reduced the withinstand competition, allowing a faster tree growth, and this may explain the relationship between the acoustic velocity and DBH in this stand. Zhang (1995) and Todaro \& Macchioni (2011) observed that the bigger trees with higher growth rate within a stand generally produced wood of lower stiffness. Chauhan \& Walker (2006) have shown that the increased diameter of fastgrowing trees, with its second moment of inertia, entails a smaller need of high material stiffness, while for trees of the same age, slow growing trees tend to have higher stiffness, enhancing tree resistance to various stresses like wind, crown weight, etc. Furthermore, younger wood has lower specific gravity and stiffness, while fast-growing trees has a larger diameter core of juvenile wood (Clark \& Daniels 2002). All the above evidences may explain how wood quality and intrinsic wood properties are generally affected by silvicultural practices, especially those affecting stand density (Fioravanti 1999, Macdonald \& Hubert 2002, Todaro 2002, Eriksson et al. 2006).

The lower wave velocity with increased DBH observed in this study appears to be associated with a higher growth rate of trees, which adversely affects specific gravity as well as the strength and stiffness of the wood. The fairly high variability detected among trees of the same DBH class (age) across different sites may reflect the natural variation between individual trees as well as the thinning effect (Wang \& Ross 2008).

Wang (1999) examined the effect of thinning treatments on both acoustic and static bending properties of young western hemlock and Sitka spruce trees from seven sites in southeast Alaska, finding that most trees with higher acoustic velocity and stiffness were growing in unthinned control stands and in stands subject to light and medium thinning, whereas the lowest values of acoustic velocity were found in heavily thinned stand.

The technology based on acoutic waves used in this study may also be applied to determine how environmental conditions and silvicultural treatments affect wood and fibre properties, thereby the most effective treatment can be selected for the desired fibre quality in future plantations (Wang 2012). Since tree DBH is easy to measure, appropriate multivariate regression models using velocity and $\mathrm{DBH}$ as predictors can be established to estimate wood quality of standing trees.

\section{Conclusions}

A strong positive association was observed between MOEd of standing trees, their DBH and the stand thinning regime (in terms of stand density) in Calabrian pine plantations in southern Italy. Moreover, our results showed that tree diameter has a significant influence on acoustic wave measurements and a significant relationship with MOEd.

Acoustics is a practical, low-cost method to assess the wood quality of standing trees (Lindstrom et al. 2009). Our results confirm that non-destructive stress wave techniques may be used to track wood property changes in standing trees, thus helping forest managers and industries in managing forest plantations to meet the desired wood and fibre qualities (Wang et al. 2001). Moreover, the information obtained by acoustic techniques may be relevant for tree breeding, pre-harvest assessment, and decision support at time of thinning. With continuous advances and refinements, this technology could assist in managing wood quality, assessing forest value, and improving the timber quality of future plantations (Wang et al. 2007b).

\section{Acknowledgments}

This study is a part of the project "ALForLab" (PON03PE_00024_1) co-funded by the National Operational Programme for Research and Competitiveness (PON R\&C) 2007-2013, through the European Regional Development Fund (ERDF) and national resource (Revolving Fund -Cohesion Action Plan [CAP] MIUR).

\section{References}

Booker R, Ridoutt BG (1997). Stiffness testing of standing trees. In: Proceedings of the " 2 nd New Zealand Wood Quality Workshop" (Ridoutt BG ed). New Zealand Forest Research Institute Ltd, FRI Bulletin, vol. 202, pp. 5-6.

Brashaw BK, Bucur V, Divos F, Goncalves R, Lu J, Meder R, Yin Y (2009). Nondestructive testing and evaluation of wood: a worldwide research update. Forest Products Journal 59 (3): 7-14.

Chauhan SS, Walker JCF (2006). Variations in acoustic velocity and density with age, and their interrelationships in radiata pine. Forest Ecology and Management 229: 388-394. - doi: 10.1016/j.foreco.2006.04.019

Chauhan SS, Entwistle KM, Walker JCF (2005). Differences in acoustic velocity by resonance and transit-time methods in an anisotropic laminated wood medium. Holzforschung 59: 428434. - doi: 10.1515/HF.2005.070

Clark A, Daniels RF (2002). Modeling the effect of physiographic region on wood properties of planted loblolly pine in southeastern United States. In: Proceedings of the 4th Workshop 
IUFRO S5.01.045. Harrison, Hot Springs (BC, Canada) 8-14 Sept 2012. Working Party S5.01-04, INRA - Centre de Researches de Nancy, France, pp. 54-60.

Divos F (2010). Acoustic tools for seedling, tree and log selection. In: Proceedings of the Final Conference of COST Action E53 "The Future of Quality Control for Wood and Wood Products". Edinburgh (Scotland) 4-7 May 2010. Napier University, Edinburgh, UK. pp. 5. [online] URL: http://www.coste53.net/downloads/Edinburgh/ Edinburgh-Presentation/51.pdf

Eriksson D, Lindberg $\mathrm{H}$, Bergsten $\mathrm{U}$ (2006). Influence of silvicultural regime on wood structure characteristics and mechanical properties of clear wood in Pinus sylvestris. Silva Fennica 40 (4): 743-762. org. - doi: 10.14214/sf.325

Fioravanti M (1999). Valutazione tecnologica dell'influenza delle pratiche selvicolturali sulla qualità del legno [Technical evaluation of the effect of silviculture on timber quality]. In: “II Legno di Castagno e di Douglasia della Toscana. Qualità del Legno e Selvicoltura, Classificazione e Valori Caratteristici del Legname Strutturale". ARSIA, Quaderno 9/99, Firenze, Italy, pp. 23-37. [in Italian]

Huang CL (2000). Predicting lumber stiffness of standing trees. In: Proceedings of the " $12^{\text {th }}$ International Symposium on Nondestructive Testing of Wood". Sopron (Hungary) 13-15 Sept 2000. University of Western Hungary, Sopron, Hungary, pp. 173-179.

Huang CL (2005). System and method for measuring stiffness in standing trees. United States Patent no. 20050005699, Weyerhaeuser Company, Washington, DC, USA, pp. 11.

Huang CL, Lambeth CC (2006). Methods for determining potential characteristics of a specimen based on stress wave velocity measurements. United States Patent no. 20060288784, Weyerhaeuser Company, Washington, DC, USA, pp. 10.

Ikeda K, Kino N (2000). Quality evaluation of standing trees by a stress-wave propagation method and its application I. Seasonal changes of moisture contents of sugi standing trees and evaluation with stress-wave propagation velocity. Mokuzai Gakkaishi 46 (3): 181-188.

Ikeda K, Arima T (2000). Quality evaluation of standing trees by a stress-wave propagation method and its application II. Evaluation of sugi stands and application to production of sugi structural square sawn timber. Mokuzai Gakkaishi 46 (3): 189-196.

Koubaa A, Zhang SY, Isabel N, Beaulieu J, Bousquet $J$ (2000). Phenotypic correlations between juvenile-mature wood density and growth in black spruce. Wood and Fiber Science 32 (1): 61-71.

Lasserre JP, Mason EG, Watt MS (2007). Assessing corewood acoustic velocity and modulus of elasticity with two impact based instruments in 11-year-old trees from a clonal-spacing experiment of Pinus radiata D. Don. Forest Ecology and Management 239: 217-221. - doi: 10.1016/j. foreco.2006.12.009

Lindstrom H, Harris P, Nakada R (2002). Methods for measuring stiffness of young trees. Holz als Roh-und Werkstoff 60: 165-174. - doi: 10.1007/s00107-002-0292-2

Lindstrom H, Reale M, Grekin M (2009). Using non-destructive testing to assess modulus of elasticity of Pinus sylvestris trees. Scandinavian Journal of Forest Research 24: 247-257. - doi: $10.1080 / 02827580902758869$

Macdonald H, Hubert J (2002). A review of the effect of silviculture on timber quality of Sitka spruce. Forestry 2: 107-138. - doi: 10.1093/fores try/75.2.107

Marziliano PA, Menguzzato G, Scuderi A, Corona $P$ (2012). Simplified methods to inventory the current annual increment of forest standing volume. iForest - Biogeosciences and Forestry 5: 276-282. - doi: 10.3832/iforo635-005

Marziliano PA, Lafortezza R, Mendicamento U, Lorusso L, Giannico V, Colangelo C, Sanesi G (2015). Estimating belowground biomass and root/short ratio of Phillyrea latifolia L. in the Mediterranean forest landscapes. Annals of Forest Science 72 (5): 585-593. - doi: 10.1007/s1 3595-015-0486-5

Nakamura N (1996). Measurement of the properties of standing trees with ultrasonics and mapping of the properties. University Forest Research Rep. 96, Faculty of Agriculture, The University of Tokyo, Tokyo, Japan, pp. 125-135. Nanami N, Nakamura N, Arima T, Okuma M (1992). Measuring the properties of standing trees with stress waves I. The method of measurement and the propagation path of the waves. Mokuzai Gakkaishi 38 (8): 739-746.

Pellerin RF, Ross RJ (2002). Nondestructive evaluation of wood. Pub. no. 7250, Forest Products Society, Madison, WI, USA, pp. 210.

Proto AR, Zimbalatti G (2016). Firewood cable extraction in the southern Mediterranean area of Italy. Forest Science and Technology 16: 1623. - doi: 10.1080/21580103.2015.1018961 Proto AR, Zimbalatti G, Bernardi B (2014). Nuovi strumenti al servizio delle utilizzazioni forestali [New tools for forest utilization]. In: Proceedings of the "II International Congress of Silviculture”. Florence (Italy) 26-29 Nov 2014. Italian Academy of Forest Sciences, Florence, Italy, pp. 1107-1112. [in Italian] - doi: 10.4129/2cis-arnuo

Sanesi G, Lafortezza R, Colangelo G, Marziliano PA, Davies C (2013). Root system investigation in sclerophyllous vetgetation: an overview. Italian Journal of Agronomy 8: 121-126. - doi: 10.408 1/ija.2013.e17

Searles G, Moore J (2009). Measurement of wood stiffness in standing trees and logs: implications for end-product quality. In: Proceedings of the COST E53 Meeting "Quality Control for Wood and Wood Products". Bled (Slovenia) 2123 Apr 2009. Holyrood, Edinburgh, UK, pp. 1-5. Sell J, Kropf F (1990). Propriétés et caractéristiques des essences de bois [Properties and characteristics of wood species]. Lignum, Le Mont-sur-Lausanne, Switzerland, pp. 93. [in French]

Todaro L, Macchioni N (2011). Wood properties of young Douglas-fir in Southern Italy: results over a 12-year post-thinning period. European Journal of Forest Research 130: 251-261. - doi: 10.1007/s10342-010-0425-9

Todaro L (2002). Influenza delle tecniche colturali sulle qualità del legno di alcune conifere con particolare riferimento alla Douglasia [Influence of silvicultural treatments on wood quality on Douglas-fir trees]. Monti e Boschi 3/4: 38-
44. [in Italian]

Tseheye A, Buchanan AH, Walker JCF (2000). Sorting of logs using acoustics. Wood Science and Technology 34: 337-344. - doi: 10.1007/soo 2260000048

UNI-ISO-3130 (1985). Legno. Determinazione dell'umidità per le prove fisiche e meccaniche [Wood. Determination of moisture content for physical and mechanical tests]. Ente Nazionale Italiano di Unificazione, Milan, Italy, pp. 2. [in Italian]

Urhan OS, Kolpak SE, Jayawickrama KJS, Howe GT (2014). Early genetic selection for wood stiffness in juvenile Douglas-fir and western hemlock. Forest Ecology and Management 320 (1): 104-117. - doi: 10.1016/j.foreco.2014.02.020

Walker JCF, Nakada R (1999). Understanding corewood in some softwoods: a selective review on stiffness and acoustics. International Forestry Review 1 (4): 251-259.

Wang X, Ross RJ (2008). Acoustic evaluation of Alaskan young-growth wood. In: Proceedings of the " $15^{\text {th }}$ International Symposium on Nondestructive Testing of Wood". Duluth (MN, USA) 10-12 Sept 2008. Forest Products Society, Madison, WI, USA, pp. 97-107.

Wang X (1999). Stress wave-based nondestructive evaluation (NDE) methods for wood quality of standing trees. PhD dissertation, Michigan Technological University, Houghton, MI, USA. pp. 187.

Wang X, Ross RJ, Mcclellan M, Barbour JR, Erickson JR, Forsman JW, McGinnis GD (2001). Nondestructive evaluation of standing trees with a stress wave method. Wood and Fiber Science 33: 522-533.

Wang X, Ross RJ, Punches J, Barbour RJ, Forsman JW, Erickson JR (2003). Evaluation of small-diameter timber for valued-added manufacturing - a stress wave approach. In: Proceedings of the "II International Precision Forestry Symposium”. Seattle (WA, USA) 15-17 Jun 2003. Institute of Forest Resources, University of Washington, Seattle, WA, USA, pp. 91-96.

Wang X, Ross RJ, Green DW, Brashaw BK, Englund K, Wolcott M (2004). Stress wave sorting of red maple logs for structural quality. Wood Science and Technology 37: 531-537. - doi: 10.1007/s00226-003-0202-8

Wang X, Carter P, Ross RJ, Brashaw BK (2007a). Acoustic assessment of wood quality of raw forest materials - a path to increased profitability. Forest Products Journal 57 (5): 6-14.

Wang X, Ross RJ, Carter P (2007b). Acoustic evaluation of wood quality in standing trees. Part I. Acoustic wave behavior. Wood and Fiber Science 39 (1): 28-38.

Wang $X$ (2011). Fundamentals of acoustic measurements on trees and logs and their implication to field application. In: Proceedings of the " $17^{\text {th }}$ International Symposium on Nondestructive Testing and Evaluation of Wood". Sopron (Hungary) 14-16 Sept 2011. University of Western Hungary, Sopron, Hungary, pp. 25-33.

Wang X (2012). Advanced sorting technologies for optimal wood products and woody biomass utilization. In: Proceedings of "International Conference on Biobase Material Science and Engineering". Changsha (China) 21-23 Oct 2012. IEEE Catalog Number CFP1240T-ART, Harbin Heilongjiang, China, pp. 175-179. 
Wang X (2013). Acoustic measurements on trees and logs: a review and analysis. Wood Science and Technology 47 (5): 965-975. - doi: 10.1007/ s00226-013-0552-9

Zhang SY (1995). Effect of growth rate on wood specific gravity and selected mechanical properties in individual species from distinct wood categories. Wood Science and Technology 29 Supplementary Material

(6): 451-466. - doi: 10.1007/BF00194204

Zimbalatti G, Proto AR (2009). Cable logging Tab. S1-Results of the Tukey' test on mean opportunities for firewood in Calabrian forest. MOEd values registered in the different Biosystems Engineering 102: 63-68. - doi: 10.101 study plots.

6/j.biosystemseng.2008.10.008

Link: Proto_2065@supplo01.pdf 